\title{
Shear Flow of Low-Viscosity Liquids in Elastic Converging Channels
}

\author{
L.A. Savin, E.A. Mashkov \\ Turgenev Oryol State University, \\ 95, Komsomolskaya ul., Oryol, 302026, Russia \\ * Corresponding author. Tel.: +7(910) 74837 66.E-mail: savin@ostu.ru
}

\begin{abstract}
The paper considers non-isothermal shear flow of a liquid in a curvilinear channel with an elastic surface. The formulation and numerical solution of the coupled thermoelastic hydrodynamic problem is presented. Modeling of the process of deformations of an elastic curvilinear plate under the action of variable hydrodynamic pressures in the shear layer by the finite element method is carried out. The regularities of the influence of various geometric, kinematic and physical parameters on the thermomechanical properties and operating modes of the system under consideration are investigated.
\end{abstract}

\section{Keywords}

Curvilinear converging channel; shear flows; thermoelastic hydrodynamic problem; verification; mathematical model; experimental studies; thermomechanical properties.

\section{Introduction}

Specific characteristics of machines can be improved by increasing the efficiency of operating processes, using new structural and lubricating materials, increasing the speed of motion of working elements, reducing weight and, in some cases, rigidity of structures. To solve the problems of vibration stability, stabilization of motion, growth of energy efficiency in the practice of engineering design, it is expedient to use elastic elements that are able to dissipate negative oscillations arising in the system. One of the most common options for the practical application of elastic elements are blade-shaped aerodynamic bearings, which ensure stable operation at frequencies of more than $1 \mathrm{kHz}$ with high energy efficiency. Despite the fact that this type of rotor support is now well-known [1-4] and it is widely used in pumping units, compressors, high-speed engines, expanders with electric and turbine drive, these devices are being actively developed.

One of the promising areas of study of bearings with elastic elements is related to the practical need for their use in supporting nodes of high-speed cryogenic turbine units, in which low temperatures and other operating conditions do not allow the use of traditional lubricants, including air. A possible solution of the problem is to use the main working media of the units as lubricants of the bearing assemblies, which requires a detailed theoretical study of the interrelated processes. The fact is that the compliance of the surface limiting the lubricant leads to a change in the pressure and temperature fields caused by the change in shape of the thin curvilinear channel under the action of external distributed loads. The analysis of the literature on this topic showed that the practical and theoretical conclusions of published scientific studies concerned only the use of gas as a lubricating medium of bladeshaped bearings [5-11]. The only exception is the experimental study of the possibility of using bladeshaped supports in turbo-pump aggregates for pumping cryogenic components of LRE fuel $[12,13]$. This paper studies the interaction of elastic and hydrodynamic forces under shear flows of lowviscosity media in thin elastic channels, which, according to the analysis of dimensionless parameters, largely corresponds to the conditions of functioning of blade-shaped bearings lubricated with liquid components. 


\section{Formulation of the thermoelastic hydrodynamic problem}

Application of elastic elements in machine units requires the development of special design tools for obtaining rational engineering solutions. A certain complexity in this case is related to complex problems of the mechanics of a deformed rigid body, dynamics, thermophysics and hydromechanics. When modeling hydromechanical systems with elastic elements, it is necessary to take into account the mutual influence of the change in the geometry of the object under investigation and dynamic and thermophysical properties of the processes occurring [14].

The design scheme of the object under study includes an absolutely rigid cylinder rotated with angular velocity, a lubricating fluid and an elastic element (blade) in the form of a sector of a cylindrical shell fixed in a stationary casing (Fig. 1). A rotating rotor pulls the wetting viscous liquid into the confluence zone between the shaft and the blade, forming a zone of increased pressure due to the pumping hydrodynamic effect. The physics of the process under consideration is in many respects identical to the phenomena in the blade-shaped bearing: the pressure in the lubricating layer deforms the blade, changing the shape of the gap, which in turn leads to a change in the pressure field.

The following designations are used in the design model: $x, y, z$ are circumferential, radial and axial directions in the cylindrical coordinate system; $h$ is a

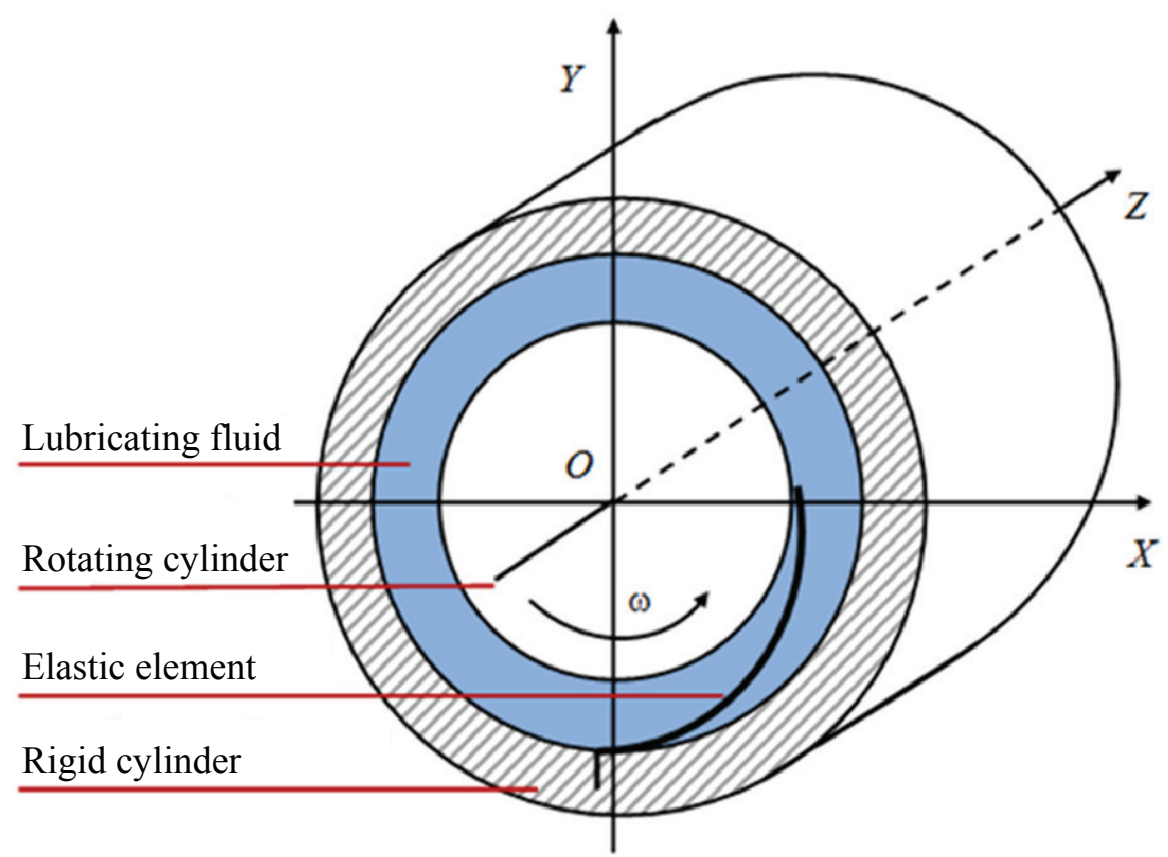

Fig. 1. Design scheme of the object under study function of the radial clearance between the rotating cylinder (rotor) and the deforming blade; $h_{0}$ is the initial clearance between the cylinder and the body; $r$, $R$ are the radii of the cylinder and the inner surface of the body; $\Delta$ - thickness of the blade; $L, b$ are length and width of the blade; $h_{n}$ is deviation of the edge of the blade; $P(x, z), T(x, z)$ are the pressure and temperature fields in the liquid layer; I, II, III are the initial, intermediate (deformed) and extreme positions of the elastic element, when it is pressed against the rigid body under the action of hydrodynamic pressures.

The following assumptions are used in the developed mathematical model for calculating elastic deformations, pressure fields, and temperatures in shear layers of a liquid:

- the cylinder and blade surfaces are absolutely solid and smooth;

- a quasistationary regime is considered, in which the angular velocity of rotation and the position of the center of the cylinder are assumed to be constant;

- the heat exchange with the environment (adiabatic flow regime of the liquid) is not taken into account;

- the thickness of the channel cross-section is small in comparison with the circumferential and axial coordinates, that is, the plane flow problem in an elastic converging channel is considered;

- the lubricating medium is a Newtonian fluid, and the change in density $\rho$, heat capacity $c_{p}$, and viscosity $\mu$ are considered to be insignificant;

- the effect of surface tension forces, inertia and gravity of the lubricant, as well as the change in the volume of the lubricant due to the temperature change, is not taken into account.

In modeling the problem of blade deformation, the assumptions of the classical linear theory of elasticity were used, in particular, the blade material is assumed to be homogeneous, isotropic, perfectly elastic, and it is a continuous medium. The smallness of possible deformations, as well as the linear connection between stresses and deformations, allows using the superposition principle for the calculation of the thermoelastic hydrodynamic problem. 
The basis of the mathematical model consists of 3 basic design relationships, namely, the Reynolds equation (1), the energy balance (2) and the elastic shell (3). The modified equation for pressures for a two-dimensional turbulent flow of a viscous incompressible fluid has the form:

$$
\frac{\partial}{\partial x}\left(\frac{h^{3}}{\mu K_{x}} \frac{\partial P}{\partial x}\right)+\frac{\partial}{\partial z}\left(\frac{h^{3}}{\mu K_{z}} \frac{\partial P}{\partial z}\right)=6 \omega r \frac{\partial(h)}{\partial x},
$$

where $\omega$ is angular velocity of rotation of the cylinder;

$$
K_{x}=1+0,044\left(k^{* 2} \mathrm{Re}\right)^{0,725}
$$

and

$$
K_{z}=1+0,0247\left(k^{* 2} \mathrm{Re}\right)^{0,65}
$$

are turbulence coefficients; $\operatorname{Re}=\frac{U \rho h_{0}^{\prime}}{\mu} \quad$ is dimensionless Reynolds number; $k^{*}=0,125 \mathrm{Re}^{0.07}$ Karman coefficient; $\rho, c_{p}, \mu$ is density, heat capacity and dynamic viscosity of the lubricating fluid.

As boundary conditions for the calculation of pressure fields, the value of the atmospheric pressure at the edges of the blade: $P(x, z)_{\in \Gamma}=P_{0}$ (Fig. 2) is taken.

In order to take into account the effect of changing the viscosity of the lubricating fluid on the pressure fields in conjunction with equation (1), it is expedient to consider the heat balance equation, which simulates the distribution of fluid temperature along the support surface to the elastic elements:

$$
\rho c_{p}\left(v_{x} \frac{\partial T}{\partial x}+v_{z} \frac{\partial T}{\partial z}\right)=\mu\left[\left(\frac{\partial v_{x}}{\partial y}\right)^{2}+\left(\frac{\partial v_{z}}{\partial y}\right)^{2}\right],
$$

where $\mu=\mu(T)$ is dependence of viscosity on temperature; $\quad v_{x}=\frac{1}{2 \mu} \frac{\partial P}{\partial x} y(y-h)+U \frac{y}{h} \quad$ and $v_{z}=\frac{1}{2 \mu} \frac{\partial P}{\partial z} y(y-h)$ are circumferential and radial projection of the flow velocity vector. he boundary condition for the temperatures is the value $T(0, \mathrm{z})=T_{0}$ at the input.

To model the stress-strain state of a curvilinear blade, we use the calculated relationships of the moment theory of cylindrical shells, which makes it possible to determine the displacement of the points of the blade given the nonaxisymmetric loading [15]:
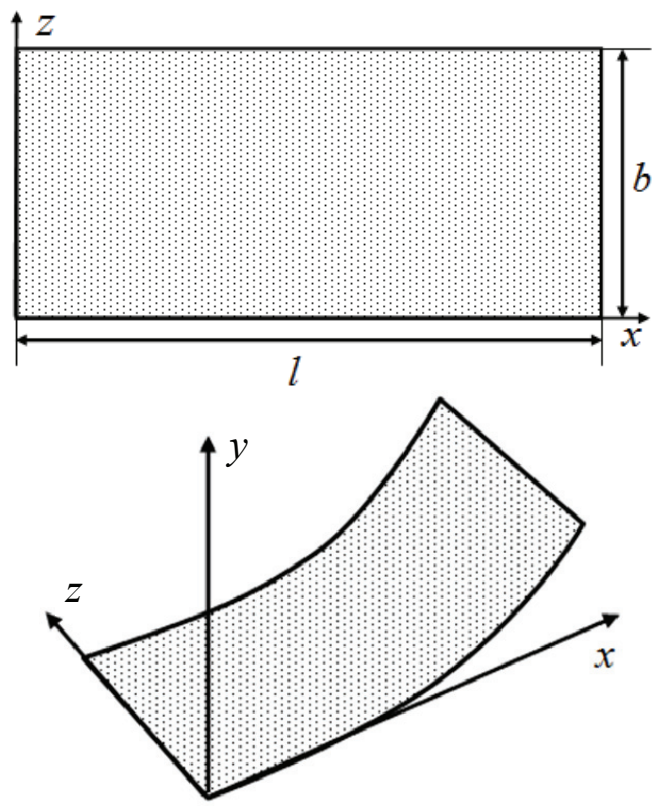

Fig. 2. Design scheme of elastic element

$$
\left\{\begin{array}{l}
\frac{\partial^{2} u}{\partial z^{2}}+\frac{1-\eta}{2 R_{o}^{2}} \cdot \frac{\partial^{2} u}{\partial \theta^{2}}+\frac{1+\eta}{2 R_{o}} \cdot \frac{\partial^{2} \vartheta}{\partial z \partial x}+\frac{\eta}{R_{o}} \cdot \frac{\partial w}{\partial z}=0 \\
\frac{1+\eta}{2 R_{o}} \cdot \frac{\partial^{2} u}{\partial z \partial x}+\frac{1}{R_{o}^{2}} \cdot \frac{\partial^{2} \vartheta}{\partial x^{2}}+\frac{1-\eta}{2} \cdot \frac{\partial^{2} \vartheta}{\partial z^{2}}+\frac{1}{R_{o}^{2}} \cdot \frac{\partial w}{\partial x}= \\
=-\frac{1-\eta^{2}}{E \Delta} P_{\tau}(x, z) \\
\frac{\eta}{R_{o}} \cdot \frac{\partial u}{\partial z}+\frac{1}{R_{o}^{2}} \cdot \frac{\partial \vartheta}{\partial x}+\frac{w}{R_{o}^{2}}++\frac{k_{1}}{R_{o}}\left[R^{3} \frac{\partial^{4} w}{\partial z^{4}}+\right. \\
\left.+2 R \frac{\partial^{4} w}{\partial z^{2} \partial x^{2}}+\frac{1}{R_{o}} \cdot \frac{\partial^{4} w}{\partial x^{4}}\right]=-\frac{1-\eta^{2}}{E \Delta} P(x, z) .
\end{array}\right.
$$

where $k_{1}=\frac{\Delta^{2}}{12 R_{\mathrm{o}}{ }^{2}} ; P_{\tau}(x, z)$ is tangential force; $E, \eta$ is Young's modulus of elasticity and the Poisson's ratio of the material of the elastic element; $u, W$ are radial and normal displacements.

As a boundary condition for the shell, it is rigidly fixed in the body along the line $(0, z)$.

Thus, in modeling the thermoelastic hydrodynamic process of fluid flow in a flat converging gap formed by a rotating cylinder and an elastic shell, in addition to equations (1) - (3), additional calculation relationships are used to determine the gap function, turbulence coefficients in the circumferential and axial directions, and also the viscosity dependence of the lubricant on the temperature [16]. The parameters to be determined are $P, T, \mu, K_{x}, K_{z}, h, u, w$. 


\section{Algorithm and software implementation}

The solution of the thermoelastic hydrodynamic problem is an iterative process, in which the problems of finding the pressure, temperature and deformation fields of an elastic element are alternately solved (Fig. 3). This approach has already been used in studies of blade-shaped gas dynamic bearings and implements the "pressure - bending - pressure" procedure, which means that even at the initial moment, in the absence of deformation of the blade, a wedge-shaped gap and a pressure field affect the elastic displacements. The change in the shape of the gap leads to the formation of a new level of pressure. The iteration cycle ends with a difference in the values of the new gap from the previous one, being an extremely small value. It is worth noting that due to the consideration of the elastic problem in the linear region of the Hooke's law, it is possible to use the principle of superposition of forces in the process of solving the problem.

To jointly solve the thermohydrodynamic and elastic problems, the Galerkin's method of weighted discrepancies in the formulation of the finite element method was used, which consists in approximating the desired pressure and temperature functions in the form of a linear combination of piecewise-defined smooth functions. As an algorithm for solving the resulting system of nonlinear equations, the Newton's iterative method was used, which involves finding corrections to the current approximations in solving simultaneous linear algebraic equations. Due to the impossibility of integrating by parts, quadratic functions were chosen as functions of the element forms in the system of nonlinear equations indicated above [14]:

$$
N_{i}^{e}=[i=(r, s)]=N_{r s}^{e}=\Lambda_{r}(x) \cdot \Lambda_{s}(y) .
$$

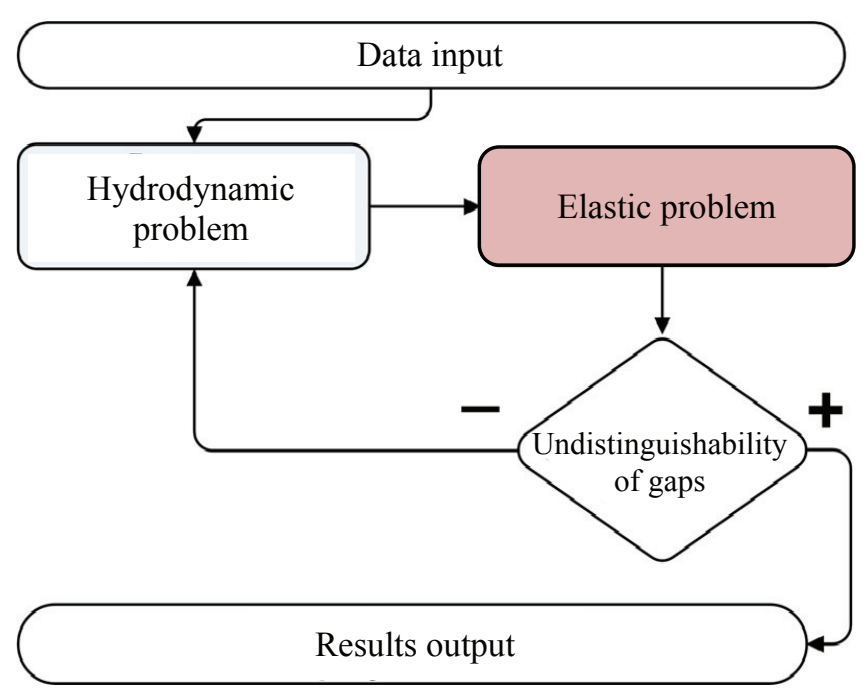

Fig. 3. Simplified procedure for solving thermoelastic hydrodynamic problem
As the factors in the expression (4), there are systems of second-order polynomials, which allow one to perform the differentiation operation more than once. Quadratic elements are represented as a rectangle with 9 nodes, so the domain of temperature and pressure fields is divided into more segments than when using linear elements. In this case, the form functions have the property of taking a value equal to one in the same node, and in all others to take zero values. To solve the thermohydrodynamic and elastic problems, a grid of $20 \times 20$ elements with 1681 nodal points was used.

The radial gap function $h$ is formed as a result of addition of the initial value with the result of solving the elastic problem of a numerical array of displacements $\{\delta\}$. The joint solution of the problem thermoelastic hydrodynamic problem is continued until the values of the deformations are less than the value of $\varepsilon \approx 0.0001 \mathrm{~m}$.

For the numerical solution of the developed mathematical model, a calculation program was created in the GNU Ocatave environment, which includes a computer experiment automation module, as well as an input-output interface for input data and simulation results. The program provides the possibility of fixing the output data both at the calculation stages and during a series of experiments. The results of the model calculation can be compared in numerical and graphic formats for different sets of physical and geometric parameters. Fig. 4 shows a window for entering initial geometric and physical parameters and a module for numbering elements and nodes of the elastic shell.

The deformation of the elastic element in the system under consideration occurs under the action of hydrodynamic forces within the radial gap between the rotating cylinder and the body. A typical form of the deviation of the blade is shown in Fig. 5.

The developed mathematical model, calculation algorithm and software have been verified by comparing the results of computational and full-scale experiments. The discrepancy between theoretical and experimental values did not exceed $14 \%$. Water and I-20A spindle oil served as lubricating media during the experimental studies. To improve the accuracy of the experimental data and to eliminate the influence of random factors, the experiment was planned and the measured values were determined using a number of repeated observations performed in sequence according to the randomization program. As a measured parameter, the magnitude of the deviation of the 


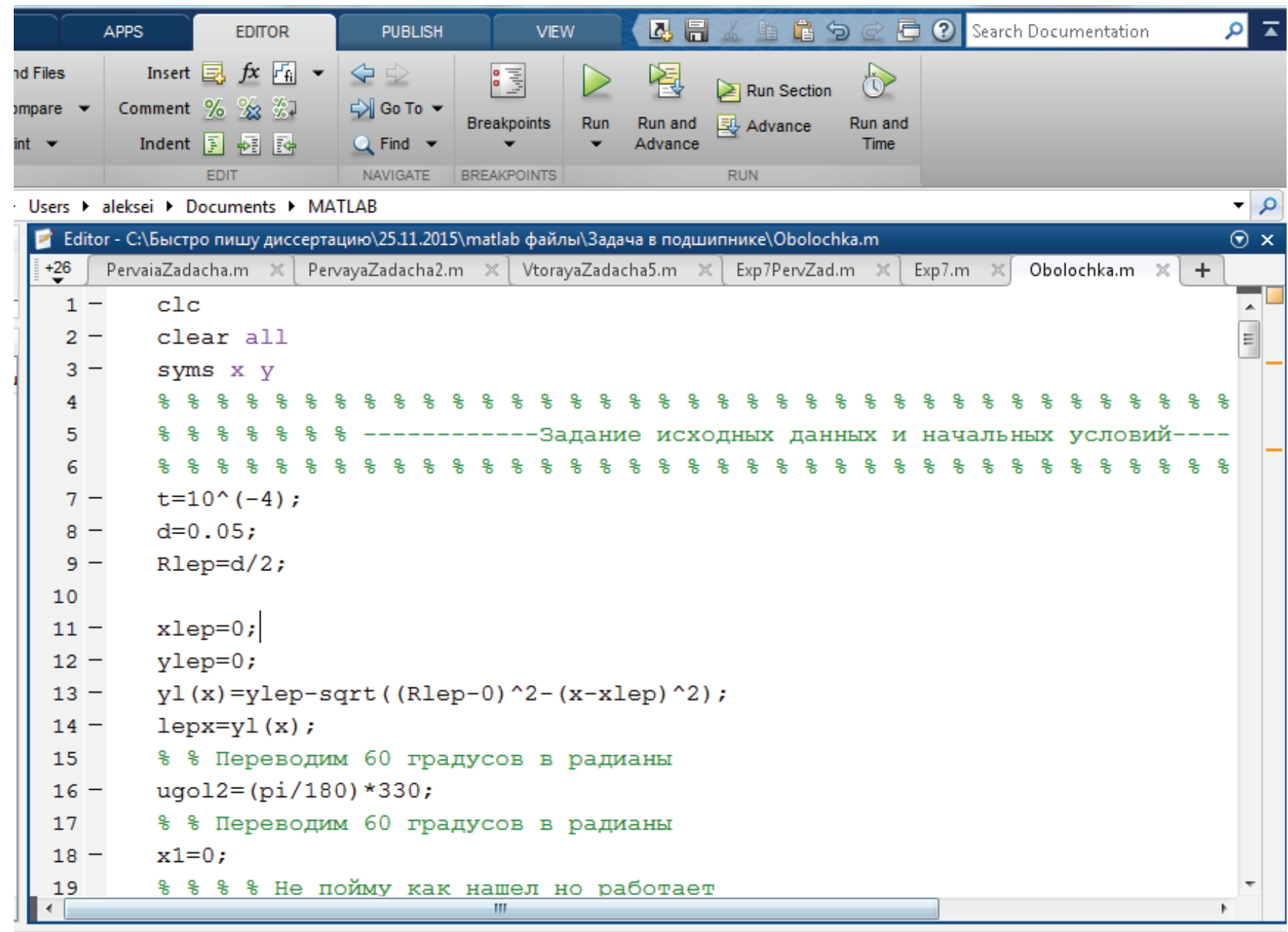

Fig. 4. Fragments of the program for calculating thermoelastic hydrodynamic problem

blade was selected by three displacement sensors. The experiment consisted in tracking the position of the blade under the action of the pressure forces of the lubricating layer, which arises from the rotation of the smooth rotor. In the course of experimental research,

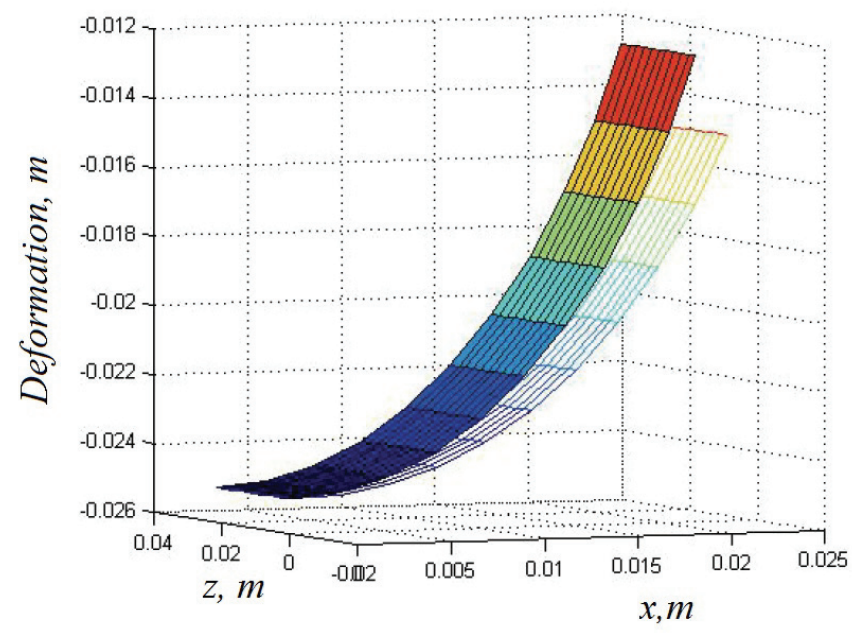

Fig. 5. Visualization of deformation of elastic element not only the state of the blade was monitored, but also other parameters of the hydromechanical process. Fig. 6 shows a comparison of the results of the fullscale experiment with the computational results when using a water lubricant.

Displacement, $\mathrm{mm}$

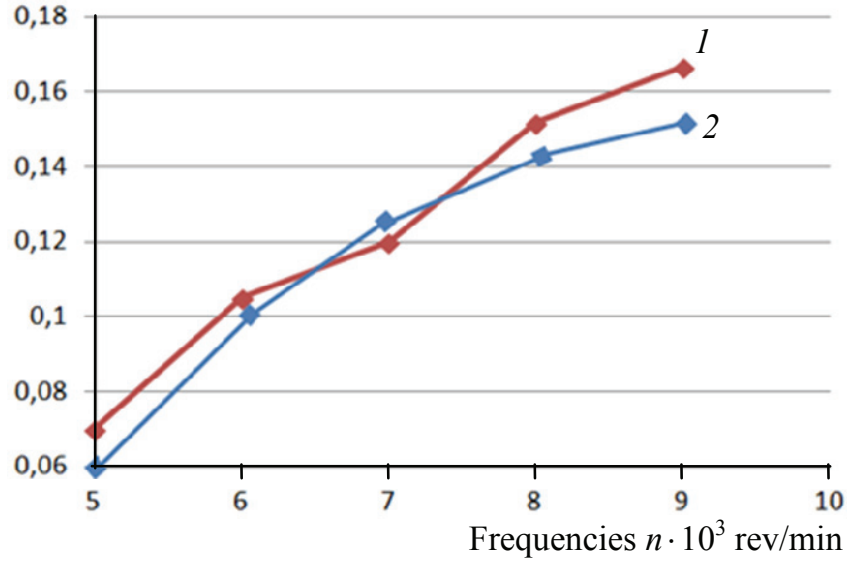

Fig. 6. Comparison of results of full-scale (1) and computational (2) experiments 


\section{Thermomechanical properties of the system}

In the computational experiments, water, I-20A oil, liquid neon and liquid nitrogen were considered as lubricants. Rotational rates of the cylinder for water and oil were $n=6 \cdot 10^{3} \mathrm{rev} / \mathrm{min}$, input temperature $T_{0}=20^{\circ} \mathrm{C}$. When calculating on liquid nitrogen, frequencies $n=50 \cdot 10^{3} \mathrm{rev} / \mathrm{min}$, temperature $T_{0}=-208^{\circ} \mathrm{C}$ were used. For all calculation options, the system parameters were $P_{0}=10^{5} \mathrm{~Pa} \cdot \mathrm{s}$, $\Delta=6 \cdot 10^{-4} \mathrm{~m}, \quad r=0.02 \mathrm{~m}, R_{\mathrm{o}}=0.02 \mathrm{~m}, E=1.8 \cdot 10^{11}$, $\eta=0.34 \mathrm{~Pa} \cdot \mathrm{s}, h_{0}^{\prime}=1.2 \cdot 10^{-4} \mathrm{~m}$.

Pressure fields serve as the basis for calculating the load-bearing capacity, rigidity and damping coefficients, trajectories of the rotors, power losses for friction in sliding bearings, and in many respects determine the performance of the technical object. The results of calculating pressures in this problem are
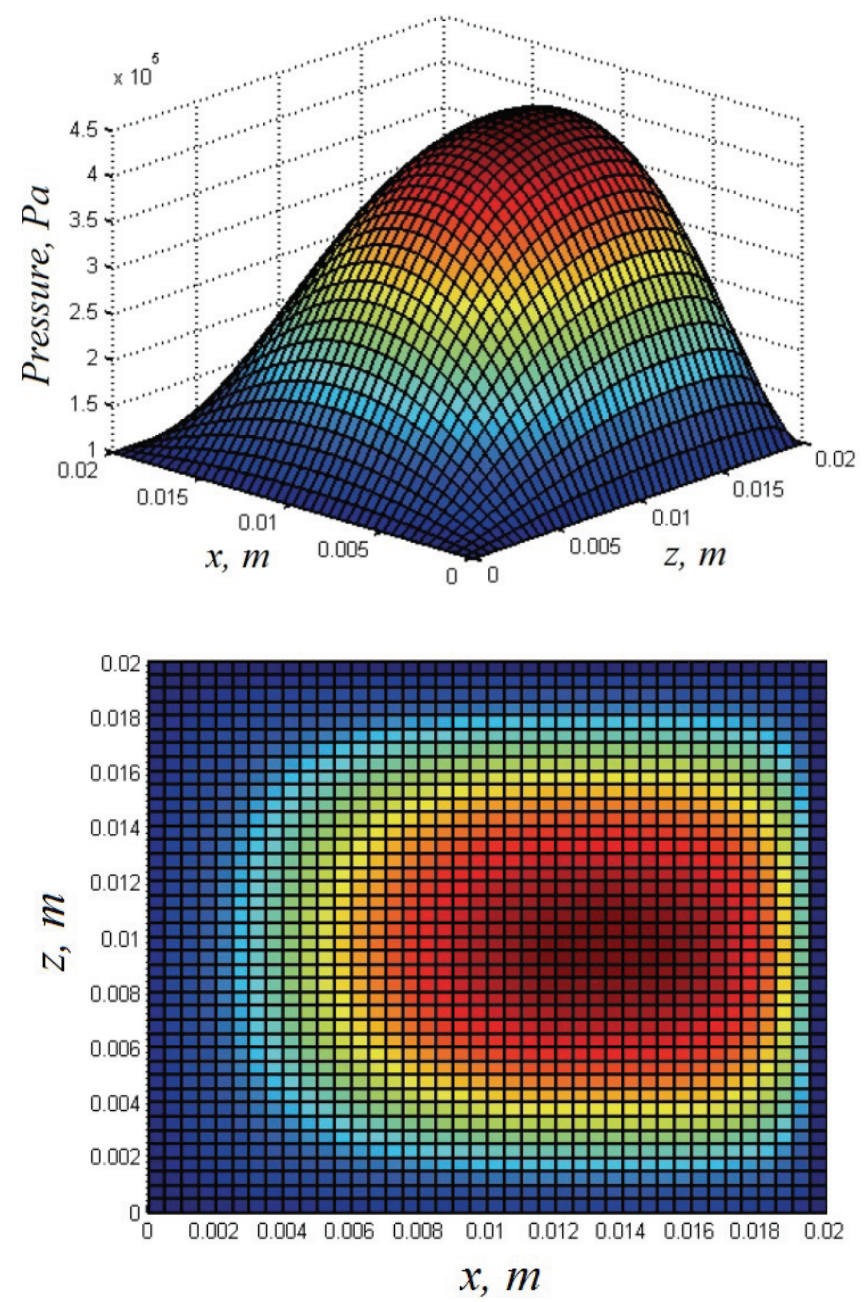

Fig. 7. Typical form of pressure fields in a layer largely due to the choice of boundary conditions. The pressure diagrams in the shear layer (Fig. 7) show that the zone of maximum pressures is formed in the middle plane at a certain distance from the minimum gap at the shear of the blade.

Figs 8-9 show the results of calculating the changes in pressure and temperature in the middle section of the blade during the flow of the two most distinct tribological and thermophysical properties. As one would expect, the level of pressure in the oil layer, due to the higher dynamic viscosity coefficient, was much higher than the pressure in the other cases considered, and with the accepted set of parameters at the extremal point it exceeded $3 \cdot 10^{6} \mathrm{MPa}$. The maximum pressure in the liquid nitrogen layer was approximately two orders of magnitude lower, which corresponded to the ratio of the dynamic viscosity of the used working fluids. There was an
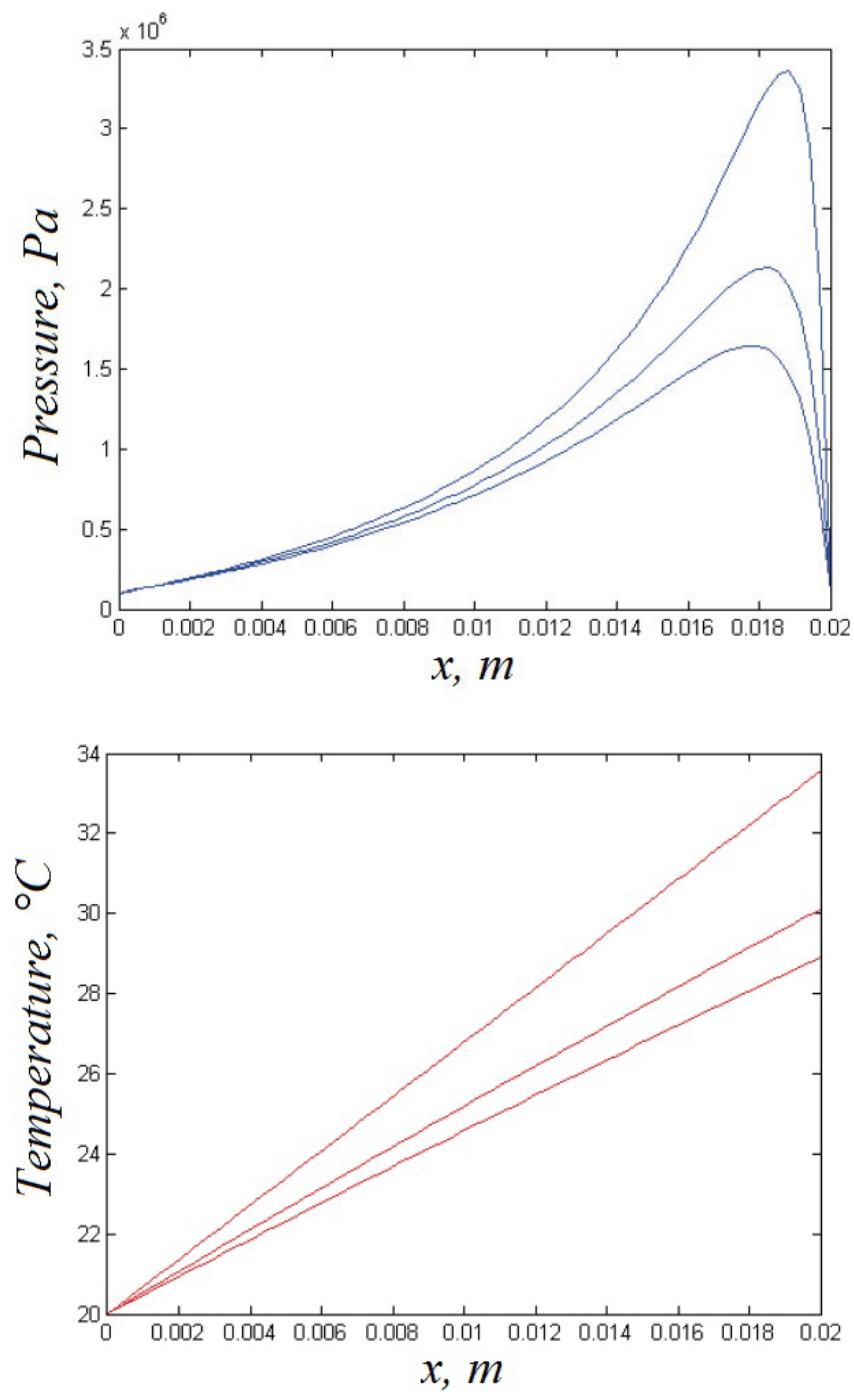

Fig. 8. Pressure and temperature in the oil layer 

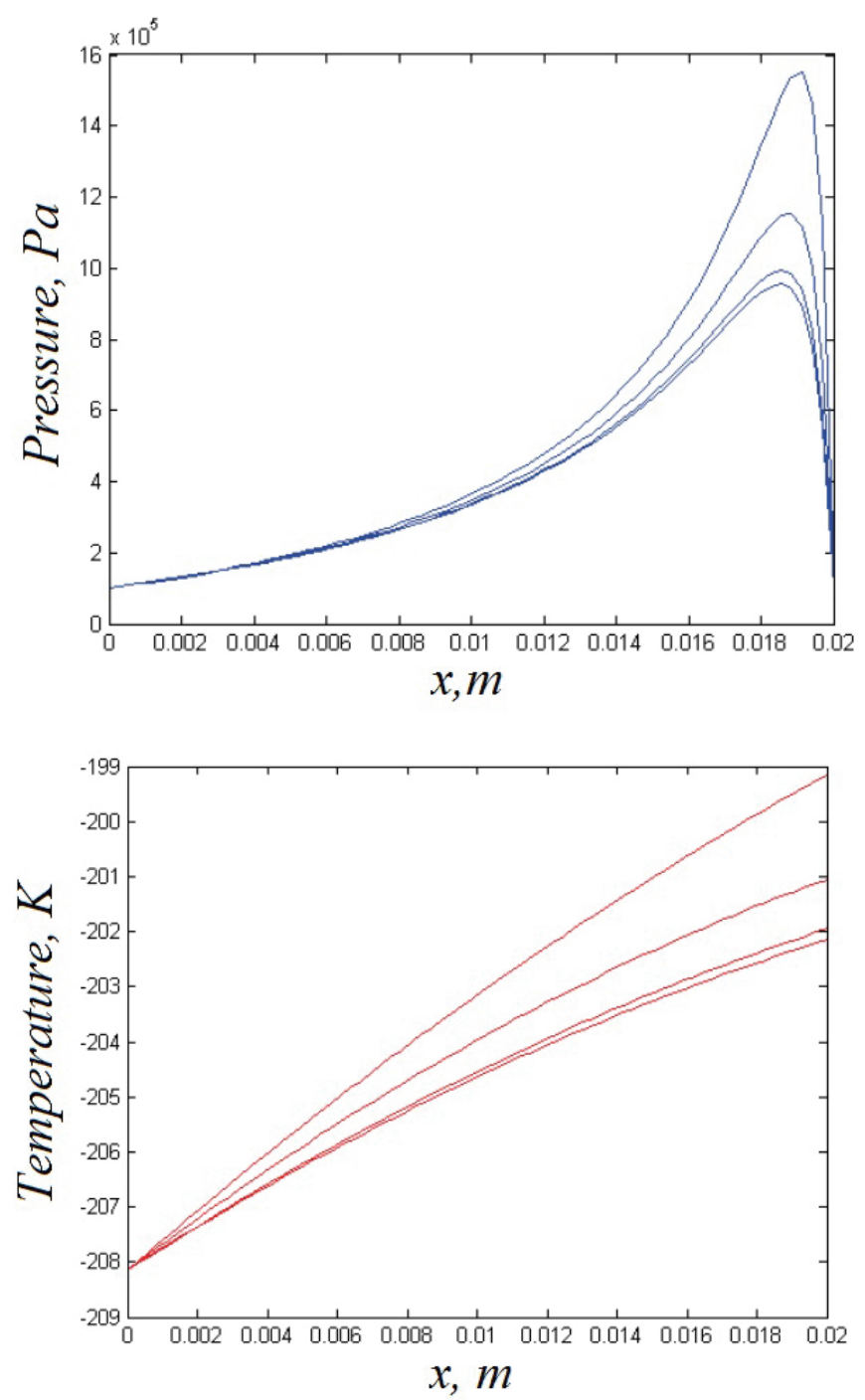

Fig. 9. Pressure and temperature in the liquid nitrogen layer

increase in temperature along the length of the blade in the oil layer for the considered values of the gaps in the range $8-14{ }^{\circ} \mathrm{C}$. In liquid nitrogen, an increase in the temperatures in the middle section of the elastic element was $4-9{ }^{\circ} \mathrm{C}$. A change in the temperature of the working fluid was $10^{\circ} \mathrm{C}$, which in turn affected the hydrodynamic reactions of the shear layer, the carrying capacity and the energy characteristics of the system. This fact indicates the need to solve the problems of calculating the blade bearings in a non-isothermal setting when using a liquid lubricant.

As can be seen from the presented results of the computational experiment, in a system where the shear flow of a fluid interacts with an elastic surface, there are interdependent processes that affect the most important characteristics in the rotor devices - pressure and temperature fields. Hence it follows that when designing real technical objects, namely, the blade bearing assemblies operating in the liquid lubrication mode, it is necessary to check the appropriateness of physical and geometrical parameters of the elastic body for the lubricating medium used, which, in turn, depends on such important bearing's characteristic as bearing capacity.

\section{Conclusion}

The main goal of the theoretical and experimental study of the hydromechanical process was to evaluate the possibility of using low-viscosity liquids as lubricants of the blade-shaped supports of the rotors in high-speed devices. The research procedure included the design of an adequate mathematical model, the choice of a rational method for numerical implementation of the algorithm, verification of the developed theoretical positions using experimental data. The main idea was to find the ratios of inertial, elastic and hydrodynamic forces that arise during a shear flow of a viscous fluid as a result of the pumping action of a rotating cylinder, and provide a non-contact mode of operation. The calculation results testify to the potential possibility of using low-viscosity liquids for the realization of the lubrication process in tribotechnical systems with elastic elements.

The research was conducted as part of the government task No. 9.2952.20917/4.6.

\section{References}

1. Snegovskij F.P. Teorija termouprugogidrodinamicheskoj smazki (teorija TUGDS) - osnova sozdanija progressivnyh tribosistem mashin [The theory of thermoelastic hydrodynamic lubrication (the theory of TEHL) as the basis for the creation of progressive tribosystems of machines]. Sborka $v$ mashinostroenii, priborostroenii [Assembly in mechanical engineering, instrument making], 2004, Vol.2, pp. 34-35. (Rus)

2. Maksimov V.A., Hadiev M.B., Fedotov E.M. Opredelenie gidrodinamicheskih i teplovyh harakteristik upornyh podshipnikov matematicheskim modelirovaniem [Determination of hydrodynamic and thermal properties of thrust bearings by mathematical modeling]. Vestnik mashinostroenija [Bulletin of Machine Building], 2004, Vol. 6, pp. 39-45. (Rus)

3. Maksimov V.A., Potanina V.L., Hadiev M.B. Raznostnyj metod reshenija periodicheskoj 
termouprugogidrodinamicheskoj (TUGD) zadachi dlja podshipnikov skol'zhenija [Difference method for solving the periodic thermoelastic hydrodynamic (TEHL) problem for sliding bearings]. Vychislitel'nye metody $i$ matematicheskoe obespechenie JeVM [Computational methods and computer software], 1981, Vol. 3, pp. 83-92. (Rus)

4. Levina G.A., Smirnov V.V. Chislennoe reshenie kraevoj zadachi o raspredelenii davlenija $\mathrm{v}$ sloe szhimaemoj smazki [Numerical solution of the boundary value problem on the distribution of pressure in a layer of compressible lubricant]. Informacionnye $i$ robototehnicheskie sistemy: Sb. nauchny trudov ChPI [Information and Robotic Systems: Col. of scientific works], Cheljabinsk: Cheljabinskij politeh, 1985, pp. 87-90. (Rus)

5. Korneev A. Ju., Savin L.A., Solomin O.V. Matematicheskaja model' neizotermicheskogo turbulentnogo techenija smazochnogo materiala $\mathrm{V}$ konicheskih oporah zhidkostnogo trenija [Mathematical model of nonisothermal turbulent flow of a lubricant in conical liquid friction bearings]. Vestnik mashinostroenija [Bulletin of Machine Building], 2005, Vol. 7, pp. 37-42. (Rus)

6. Kodnir D.S., Vasin V.N. Reshenie neizotermicheskoj kontaktno-gidrodinamicheskoj zadachi pri chistom kachenii i uchete teplootvoda vdol' i poperek smazochnogo sloja [Solution of the nonisothermal contact-hydrodynamic problem in pure rolling and given the heat sink along and across the lubricating layer]. Tezisy dokl. vsesojuznoj konferencii trenija $i$ iznos $v$ mashinah [Proc.of All-Union Friction Conference and Wear in Machines]. Cheljabinsk: 1979, pp. 154-156. (Rus)

7. Cheng H.S. A refined solution of the thermal elastohydrodinamic lubrication of rolling and sliding cylinders. ASME transactions, 1965, Vol. 8, pp. 47-58.

8. DellaCorte C. The evaluation of a modified chrome oxide based high temperature solid lubricant coating for foil gas bearings. Tribology Transactions, 2000, Vol. 43(2), pp. 257-262.
9. Dowson D. A numerical procedure for the solution of the EHD problem on rolling and sliding contacts lubricated by a Newtonian fluid. Proc. Inst. Mech. Engrs., 1965, pp. 77-82.

10. Fillon M., Bligoud J.C., Frene J. Experimental study of tilting-pad journal bearings - comparison with theoretical thermoelastohydrodynamic results. ASME J. Tribol., 1992, Vol. 114, pp. 579-588.

11. Heshmat H., Walowit J.A., Pinkus O. Analysis of gas-lubricated foil journal bearings. Journal of Lubrication Technology, 1983, Vol. 105, pp. 647- 655 .

12. Kudish A. Asymptotic method of study for plane problems of the elastohydrodynamic lubrication theory for heavily loaded regime. Part 2. Nonisothermal problem. Proc. Acad. Sci., 1983, Vol. 36(5), pp. 47-59.

13. Wang Y.S. et al. TEHD analysis of journal bearing under severe operating conditions. Tribol. Int., 2002, Vol. 35(6), pp. 395-407.

14. Savin L.A., Mashkov E.A., Kornaev A.V. Modelirovanie neizotermicheskogo techenija zhidkosti $\mathrm{v}$ uprugom kanale peremennoj geometrii [odeling of nonisothermal fluid flow in an elastic channel of variable geometry]. Izvestija TulGU. serija: Tehnicheskie nauki [Bulletin of Tula State University. Series: Engineering science], 2015, Vol. 7-2, pp. 49-63. (Rus)

15. Mashkov E.A. Uprugo-gidrodinamicheskaja zadacha modelirovanija lepestkovogo podshipnika $\mathrm{v}$ vysokoskorostnyh rotornyh sistemah [Elastichydrodynamic problem of simulation of the blade bearing in high-speed rotor systems]. Fundamental'nye $i$ prikladnye problemy tehniki $i$ tehnologii. serija: Estestvennye nauki [Fundamental and applied problems of engineering and technology. Series: Natural Sciences], 2015, Vol. 2, pp. 28-35. (Rus)

16. Korovchinskij M.V. Prikladnaja teorija podshipnikov zhidkostnogo trenija: uchebnoe posobie [Applied theory of fluid friction bearings: a tutorial]. M.: Mashgiz, 1954, 188 p. (Rus) 